\title{
EFEITO DA ROTAÇÃO DE CULTURAS, ADUBAÇÃO VERDE E NITROGENADA SOBRE O RENDIMENTO DO FEIJÃO ${ }^{1}$
}

\author{
ORIVALDO ARF ${ }^{2}$, LUZIA SALUSTIANO DA SILVA ${ }^{3}$, SALATIÉR BUZETTI \\ MARLENE CRISTINAALVES ${ }^{4}$, MARCO EUSTÁQUIO DE SÁ ${ }^{2}$, \\ RICARDO ANTONIO FERREIRA RODRIGUES ${ }^{4}$ e FERNANDO BRAZ TANGERINO HERNANDEZ ${ }^{4}$
}

\begin{abstract}
RESUMO - O presente trabalho foi conduzido na região de Selvíria, MS, e teve como objetivo avaliar o efeito da incorporação de mucuna-preta, lab-lab e restos culturais de milho no desenvolvimento e produção do feijão (Phaseolus vulgaris L.) de inverno. O delineamento experimental foi o de blocos ao acaso; os tratamentos foram constituídos pela combinação do efeito da incorporação de restos culturais do milho, mucuna-preta e lab-lab no desenvolvimento do feijoeiro, na presença e ausência de adubação nitrogenada em cobertura. Pelos resultados obtidos nas condições experimentais, pode-se concluir que a incorporação de mucuna-preta praticamente dobrou a produção de grãos de feijão em relação ao tratamento com incorporação apenas de palhada de milho; as maiores produtividades foram obtidas nos tratamentos com incorporação de mucuna-preta, lab-lab e milho + mucuna-preta semeada 100 dias após a semeadura do milho, e a aplicação de $45 \mathrm{~kg} \mathrm{ha}^{-1}$ de $\mathrm{N}$ aumentou em 17,8\% a produtividade do feijoeiro.
\end{abstract}

Termos para indexação: restos culturais, aplicação de nitrogênio, sucessão de culturas.

EFFECTS OF CROP ROTATION, GREEN MANURE, AND NITROGEN FERTILIZER ON THE BEAN YIELD

\begin{abstract}
The present work was carried out at Selvíria, MS, Brazil, with the objective of evaluating the effects of velvetbean, lab-lab and corn crop residues on the development and yield of winter bean (Phaseolus vulgaris L.) crops. The experimental design utilized was a randomized blocks obtained through an arrangement between the incorporation of different organic residues, with and without nitrogen supply in the bean crop. Grain yield was higher when velvetbean was incorporated in rotation with corn crop residues. The best yield was obtained in the treatments: velvetbean incorporation, lab-lab and corn + velvetbean sowed 100 days after corn sowing. Application of $45 \mathrm{~kg} \mathrm{ha}^{-1}$ of $\mathrm{N}$ fertilizer (urea) increased the yield of winter bean crops in $17,8 \%$.
\end{abstract}

Index terms: organic residues, nitrogen supply, bean crop rotation.

\section{INTRODUÇÃO}

A adubação verde com leguminosas proporciona vantagens, como a economia com fertilizantes nitrogenados, grande rendimento por área, sistema radicular profundo, que ajuda a descompactar o solo,

\footnotetext{
${ }^{1}$ Aceito para publicação em 10 de fevereiro de 1999 Apoio financeiro da FAPESP e do CNPq.

${ }^{2}$ Eng. Agr., Dr., Dep. de Fitotecnia, Economia e Sociologia Rural, Faculdade de Engenharia, UNESP, Av. Brasil no 56 , Caixa Postal 31, CEP 15385-000 Ilha Solteira, SP. E-mail: gd@adm.feis.unesp.br

${ }^{3}$ Eng ${ }^{\mathrm{a}}$ Agr $\stackrel{\mathrm{a}}{\mathrm{a}}$, Faculdade de Engenharia, UNESP.

${ }^{4}$ Eng. Agr., Dr., Dep. de Ciência do Solo e Engenharia Rural, Faculdade de Engenharia, UNESP.
}

e simbiose com bactérias fixadoras de nitrogênio (Silva et al., 1985). Já a rotação de culturas pode ser citada como benéfica à melhoria das condições físicas, químicas e biológicas do solo, ao controle de plantas daninhas, bem como ao de doenças e pragas, à reposição de restos orgânicos, e à proteção do solo contra a ação dos agentes climáticos; é recomendável usar espécies das plantas fixadoras de nitrogênio com sistema radicular profundo ou abundante, espécies capazes de aproveitar os fertilizantes residuais das culturas comerciais; para o Paraná, indica-se como cobertura vegetal o lab-lab, mucunas, crotalárias e guandu para cultivos de verão (IAPAR, 1995). O manejo da matéria orgânica mediante rotação de culturas, adubação verde e consorciação 
de culturas pode proporcionar melhor aproveitamento de adubos químicos e possibilitar redução nos custos com adubação nitrogenada mineral, uma vez que propicia aumento da atividade biológica do solo (Hernani et al., 1995).

Miyasaka et al. (1966), estudando o comportamento de massa vegetal de leguminosas e gramíneas em decomposição e alguns efeitos na cultura do feijoeiro quando incorporadas ao solo antes da semeadura do feijão, verificaram várias vantagens da incorporação, como maior retenção de umidade e menor variabilidade térmica do solo, embora em menor grau do que no solo com cobertura morta (mulch), e aumento no teor de K nas folhas, no desenvolvimento da parte vegetativa e radicular, e na produtividade do feijoeiro. Já Galeti (1973), citado por Silva et al. (1985), sugere que a adubação verde melhora o aproveitamento dos fertilizantes minerais, proporcionando aumentos na produção, porque o adubo verde mobiliza os nutrientes das camadas mais profundas, tornando-os disponíveis para as culturas subseqüentes. Kiehl (1985) afirma que os adubos verdes, ao absorverem os nutrientes do solo, contribuem para a redução das perdas por lixiviação. $\mathrm{O}$ autor recomenda, ainda, não atrasar a implantação da cultura comercial, pois os adubos verdes após incorporação tendem a se decompor e a liberar rapidamente os nutrientes. Já Alvarenga et al. (1995) afirmam que o fato de uma espécie reter grande quantidade de nutrientes não significa que eles estejam prontamente disponíveis à cultura seguinte.

Um exemplo típico da deficiência de incorporação de restos vegetais para a cultura do feijoeiro, segundo Bulisani et al. (1987), é observado em extensas áreas sob cerrado no Brasil Central e no Oeste Paulista, onde a produtividade das plantas é razoável quando cultivadas em solos que tenham recebido fitomassa, especialmente, leguminosas. Hernani et al. (1995) sugerem ser a matéria orgânica capaz de influenciar de forma positiva a retenção de nutrientes de plantas e diminuir as perdas por lixiviação; mas, segundo o autor, o efeito mais importante da decomposição de restos vegetais é a melhoria da estrutura do solo, que, conseqüentemente, melhora a relação água/ar, além de permitir aumentos da infiltração de água, da retenção de água e nutrientes no solo, e desenvolvimento mais adequado das raízes. Além disso, a melhoria na estrutura proporciona maior controle da erosão hídrica. Nascimento (1994), citado por Donegá (1994), estudando mucuna-preta, lablab e Crotalaria juncea na proteção do solo, concluiu que as leguminosas apresentaram níveis diferentes de proteção ao solo, sendo, no geral, mais efetivas a partir dos 60 dias; contudo, a mucunapreta ofereceu melhor proteção do solo contra a erosão.

Na decomposição dos adubos verdes incorporados observam-se grandes reduções nas populações dos patógenos fúngicos das plantas, auxiliando no controle de doenças (Garret (1956, 1965), Stover (1962) e Patrick \& Tousson (1965), citados por Sharma, 1982). Os autores constataram que a manutenção da matéria orgânica do solo é muito importante para o controle de nematóides. Verificaram também que todos os adubos verdes estudados (crotalária, lab-lab, mucuna e outros) foram altamente eficientes na redução da população ativa de nematóides fitoparasitas e saprófagos, sendo que o controle pareceu estar mais associado à produção de toxinas pelos adubos verdes do que pela produção de massa seca; sugerem ser a adubação verde um dos métodos mais baratos de controle de nematóides. Segundo Ferraz et al. (1977), citados por Tanaka et al. (1992), a mucuna-preta pode controlar nematóides e algumas espécies de plantas daninhas. Kramm et al. (1990) afirmam ser necessário manter a cultura do feijoeiro livre de plantas daninhas durante 30 dias após emergência; e o uso de adubos verdes possibilita diminuir o uso de herbicidas ou capinas (Chabaribery, 1988). Contudo, Abboud \& Duque (1986) observaram que a mucuna-preta aparentemente proporciona efeitos alelopáticos negativos sobre o feijão, apesar de apresentar efeitos benéficos sobre o milho. Mas, convém ressaltar que o mais importante é que a adubação orgânica proporciona benefícios residuais.

Segundo Fageria (1983), a capacidade intrínseca de produção agrícola dos solos está íntima e diretamente relacionada com os seus teores de matéria orgânica e N. Por outro lado, é difícil manter um nível satisfatório dos dois componentes na maioria dos solos cultivados. Assim, os métodos de adição e de manutenção de matéria orgânica devem ser 
considerados com antecipação em todos os programas de manejo dos solos cultivados. A matéria orgânica pode ser adicionada aos solos cultivados de diversos modos, como, por exemplo, mediante adubação verde e restos de culturas.

O presente trabalho teve como objetivo avaliar o efeito da adubação verde e nitrogenada sobre o rendimento do feijão, na região de Selvíria, MS, em solo originalmente sob vegetação de cerrado.

\section{MATERIAL E MÉTODOS}

O trabalho foi instalado em área experimental pertencente à Faculdade de Engenharia de Ilha Solteira, UNESP, localizada no município de Selvíria, MS, tendo como coordenadas geográficas $51^{\circ} 22^{\prime}$ de longitude Oeste de Greenwich e $20^{\circ} 22^{\prime}$ de latitude Sul, com altitude de 335 metros. O solo do local é do tipo Latossolo Vermelho-Escuro, epi-eutrófico álico, textura argilosa. A precipitação média anual é de $1.370 \mathrm{~mm}$, a temperatura média anual é de $23,5^{\circ} \mathrm{C}$, e a umidade relativa do ar está entre $60 \%$ e $70 \%$.

Antes da instalação do experimento, foram coletadas amostras de solo, para determinação das características químicas. O preparo do solo foi realizado através de uma aração e duas gradagens, sendo a primeira logo após a aração, e a segunda, pouco antes da semeadura. A semeadura do milho foi realizada mecanicamente, no dia 7.12.94, utilizando-se o espaçamento de $0,90 \mathrm{~m}$ entre linhas, e cerca de 6 a 7 sementes $\mathrm{m}^{-1}$ de sulco, de maneira a obter, após a emergência da cultura, uma população de aproximadamente 50.000 plantas ha ${ }^{-1}$. O híbrido utilizado foi o Cargill 125 .

A mucuna-preta e o lab-lab no sistema de cultivo solteiro foram semeados sem adubação, também no espaçamento de 0,90 m e utilizando-se 7 e 10 sementes viáveis $\mathrm{m}^{-1}$, respectivamente. Posteriormente, aos 75 e 100 dias após a emergência do milho, foram semeadas a mucuna-preta e o lab-lab em suas entrelinhas, de maneira semelhante à do cultivo solteiro

Após a colheita do milho, na época de florescimento pleno da mucuna-preta ou lab-lab, em cada tratamento, a área foi roçada mecanicamente, e, posteriormente, quando a mucuna-preta semeada aos 100 dias após a semeadura do milho atingiu a época de florescimento pleno, realizou-se uma gradagem pesada na área, para incorporação das plantas de milho, lab-lab e mucuna-preta (os valores médios da matéria seca incorporada estão apresentados na Tabela 1). Em seguida, o solo foi preparado com uma aração e duas gradagens, sendo a primeira gradagem logo após a aração, e a segunda, pouco antes da semeadura.
A semeadura do feijão, cultivar IAC Carioca, foi realizada mecanicamente em 4.7.95, nas parcelas onde anteriormente existia milho, milho + mucuna-preta, milho + lablab, mucuna-preta e, lab-lab. A adubação básica foi constituída por $280 \mathrm{~kg} \mathrm{ha}^{-1}$ da formulação $4-30-10+0,4 \% \mathrm{Zn}$. Utilizou-se o espaçamento de $0,50 \mathrm{~m}$ entrelinhas e cerca de 15 a 16 sementes $\mathrm{m}^{-1}$ de sulco, com o objetivo de se obter posteriormente uma população de 250.000 plantas ha $^{-1}$

O delineamento experimental foi o de blocos ao acaso, e os tratamentos, constituídos pela combinação do efeito da incorporação de restos culturais de milho, mucuna-preta e lab-lab, no desenvolvimento do feijoeiro, na presença e ausência de adubação nitrogenada em cobertura. A adubação nitrogenada em cobertura foi realizada aos 24 dias após a emergência das plantas, utilizando $45 \mathrm{~kg} \mathrm{ha}^{-1} \mathrm{de} \mathrm{N}$ (uréia), em parte da parcela. Portanto, cada parcela (tratamento principal) constou de 18 linhas de feijão com $10 \mathrm{~m}$ de comprimento e subdivididas no sentido longitudinal, em duas subparcelas, ou seja, tratamento secundário constituído pela aplicação, ou não, de N, na forma de uréia.

O controle de plantas daninhas foi realizado mediante aplicação do herbicida pendimenthalin $\left(1.000 \mathrm{~g} \mathrm{ha}^{-1}\right.$ do i.a.) em pré-emergência, e bentazon ( $720 \mathrm{~g} \mathrm{ha}^{-1}$ do i.a. $)$, 23 dias após a emergência das plantas.

Por ocasião do florescimento das plantas de feijão, foram coletadas amostras de solo na profundidade de 0-20 cm na área útil das parcelas, para determinação das características químicas, de acordo com a metodologia de Raij \& Quaggio (1983). As características físicas foram avaliadas, com duas repetições por parcela, nas profundidades de 0-10, 10-20, 20-30 e 30-40 cm, sendo usada a metodologia de densidade (Blake \& Hartge, 1986), e, macro e microporosidade (Vomocil, 1965).

Durante o desenvolvimento da cultura foram realizados os demais tratos culturais e fitossanitários, recomendados para a cultura do feijão.

Por ocasião do florescimento pleno das plantas, foram coletadas, ao acaso, dez plantas da área útil de cada subparcela, e levadas ao laboratório, acondicionadas em sacos de papel devidamente identificados, e colocadas para secagem em estufa de ventilação forçada à temperatura de $60-70^{\circ} \mathrm{C}$, até atingir peso em equilíbrio.

Para avaliação dos teores de macronutrientes foram utilizadas as folhas das plantas coletadas para a avaliação anterior. Após a secagem em estufa de ventilação forçada, o material foi submetido à moagem em moinho do tipo Willey e, posteriormente, sofreu digestões sulfúrica e nitroperclórica, conforme metodologia proposta por Sarruge \& Haag (1974).

Por ocasião da colheita, foram coletadas dez plantas em local predeterminado, na área útil de cada subparcela para 
determinação de: número de vagens/planta, determinado pela relação número total de vagens/número de plantas; número de grãos/planta, avaliado pela relação número total de grãos/número de plantas; número de grãos/vagem, obtido pela relação número total de grãos/número total de vagens; peso de 100 grãos, determinado através da coleta ao acaso e pesagem de duas amostras de 100 grãos de cada subparcela.

As plantas da área útil de cada subparcela foram arrancadas e deixadas para secagem a pleno sol. Após a secagem, foram submetidas a trilhagem mecânica, e os grãos obtidos foram pesados, e os dados, transformados em $\mathrm{kg} \mathrm{ha}^{-1}$ (13\% base úmida).

\section{RESULTADOS E DISCUSSÃO}

Os resultados obtidos na análise das características físicas das amostras de solo retiradas na época de florescimento do feijão estão apresentados na Tabela 2, onde pode ser observado que não houve diferenças significativas entre os tratamentos nos diversos parâmetros estudados. Entretanto, verifica-se que a porosidade total foi mais alta na profundidade de $0-10 \mathrm{~cm}$, com ligeira queda nas profundidades 10-20 e 20-30 cm, e posterior aumento na profundidade de $30-40 \mathrm{~cm}$. Isto se deve, provavelmente, à concentração das raízes do feijão nessas profundidades $(10-30 \mathrm{~cm})$.
Os resultados obtidos na análise química de amostras de solo retiradas na época de florescimento do feijão estão apresentados na Tabela 3 . Analisando o parâmetro porcentagem de matéria orgânica, verifica-se que, apesar de terem sido incorporadas ao solo diferentes quantidades de matéria seca (Tabela 1), não houve diferenças significativas no seu teor, nos diferentes tratamentos utilizados. As explicações prováveis são de que houve a mineralização e posterior consumo pela cultura, ou o tempo decorrido entre a incorporação dos adubos verdes e a avaliação realizada não foi suficiente para que ocorresse a adequada decomposição do material orgânico. Por outro lado, Kiehl (1985) afirma que os adubos verdes, após incorporados, tendem a se decompor e a liberar rapidamente os nutrientes. Quanto aos demais parâmetros de fertilidade do solo, de um modo geral, não se observam diferenças entre os tratamentos utilizados, com exceção do $\mathrm{K}$, em que o tratamento com milho apresentou o maior teor, os tratamentos com adubos verdes (mucuna-preta ou lab-lab) obtiveram valores menores, e os tratamentos com milho + adubo verde, teores intermediários. De maneira geral, pode-se dizer que as características químicas do solo no momento de maior exigência em nutrientes, ou seja, florescimento e frutificação da cultura, eram favoráveis ao cultivo.

TABELA 1. Valores médios da matéria seca do milho, mucuna-preta e lab-lab em cultivo solteiro ou consorciado, na região de Selvíria, MS, 1994/95².

\begin{tabular}{lcccc}
\hline \multirow{2}{*}{ Tratamento } & \multicolumn{2}{c}{ Milho } & $\begin{array}{c}\text { Mucuna-preta ou lab-lab } \\
\left(\mathrm{kg} \mathrm{ha}^{-1}\right)\end{array}$ & $\begin{array}{c}\text { Matéria seca total } \\
\left(\mathrm{kg} \mathrm{ha}^{-1}\right)\end{array}$ \\
\cline { 2 - 3 }$\left(\mathrm{g} \mathrm{planta}^{-1}\right)$ & $\left(\mathrm{kg} \mathrm{ha}^{-1}\right)$ & - & $4.290 \mathrm{~d}$ \\
Milho & 83,63 & 4.290 & $6.321 \mathrm{a}$ & $11.116 \mathrm{a}$ \\
Milho + mucuna-preta aos 75 DAS & 93,47 & 4.795 & $3.695 \mathrm{~b}$ & $8.372 \mathrm{~b}$ \\
Milho + mucuna-preta aos 100 DAS & 91,15 & 4.676 & $973 \mathrm{c}$ & $5.555 \mathrm{~cd}$ \\
Milho + lab-lab aos 75 DAS & 91,76 & 4.707 & $123 \mathrm{c}$ & $4.390 \mathrm{~d}$ \\
Milho + lab-lab aos 100 DAS & 83,17 & 4.266 & $7.340 \mathrm{a}$ & $7.340 \mathrm{bc}$ \\
Lab-lab & - & - & $7.974 \mathrm{a}$ & $7.974 \mathrm{~b}$ \\
Mucuna-preta & - & - & 17,61 & 14,12 \\
\hline C.V. $(\%)$ & 11,74 & 11,74 &
\end{tabular}

${ }^{1}$ Médias seguidas de mesma letra, na coluna, não diferem estatisticamente entre si pelo teste de Tukey a $5 \%$ de probabilidade

2 Dias após a semeadura do milho. 
TABELA 2. Características físicas de amostras de solo retiradas na época de florescimento do feijão, em decorrência da incorporação dos restos culturais de milho, mucuna-preta e lab-lab, na região de Selvíria, MS, 1995.

\begin{tabular}{|c|c|c|c|c|c|c|c|c|}
\hline \multirow[t]{2}{*}{ Tratamento } & \multicolumn{8}{|c|}{ Profundidade $(\mathrm{cm})$} \\
\hline & $0-10$ & $10-20$ & $20-30$ & $30-40$ & $0-10$ & $10-20$ & $20-30$ & $30-40$ \\
\hline & \multicolumn{4}{|c|}{----- Macroporosidade (\%) ------ } & \multicolumn{4}{|c|}{----- Microporosidade (\%) ------- } \\
\hline Milho & 15,97 & 12,88 & 10,82 & 12,68 & 35,44 & 33,55 & 33,61 & 34,73 \\
\hline Milho + mucuna-preta aos 75 DAS $^{1}$ & 16,46 & 8,87 & 10,59 & 13,11 & 34,57 & 36,67 & 34,01 & 34,45 \\
\hline Milho + mucuna-preta aos 100 DAS & 16,18 & 7,35 & 9,67 & 11,03 & 35,82 & 35,93 & 33,91 & 35,24 \\
\hline Milho + lab-lab aos 75 DAS & 19,01 & 11,88 & 7,12 & 11,79 & 33,71 & 37,07 & 34,37 & 34,55 \\
\hline Milho + lab-lab aos 100 DAS & 18,96 & 8,70 & 9,34 & 12,32 & 34,14 & 38,05 & 34,32 & 35,52 \\
\hline Lab-lab & 18,32 & 12,02 & 10,39 & 12,15 & 33,40 & 36,29 & 34,57 & 35,39 \\
\hline Mucuna-preta & 16,36 & 10,51 & 8,86 & 11,20 & 36,51 & 38,51 & 35,52 & 35,80 \\
\hline \multirow[t]{2}{*}{ C.V. $(\%)$} & 29,04 & 35,05 & 37,25 & 20,35 & 7,97 & 6,12 & 5,15 & 3,33 \\
\hline & \multicolumn{4}{|c|}{--------- Porosidade total $(\%)$-------- } & \multicolumn{4}{|c|}{------- Densidade $\left(\mathrm{g} \mathrm{cm}^{-3}\right)$------- } \\
\hline Milho & 51,41 & 46,44 & 44,42 & 48,16 & 1,24 & 1,39 & 1,41 & 1,31 \\
\hline Milho + mucuna-preta aos 75 DAS & 51,03 & 45,54 & 44,60 & 47,60 & 1,22 & 1,42 & 1,41 & 1,34 \\
\hline Milho + mucuna-preta aos 100 DAS & 52,00 & 43,27 & 43,58 & 46,18 & 1,25 & 1,48 & 1,45 & 1,35 \\
\hline Milho + lab-lab aos 75 DAS & 52,71 & 48,95 & 41,49 & 46,34 & 1,20 & 1,36 & 1,47 & 1,35 \\
\hline Milho + lab-lab aos 100 DAS & 53,10 & 46,74 & 44,68 & 47,97 & 1,17 & 1,38 & 1,44 & 1,33 \\
\hline Lab-lab & 51,72 & 48,49 & 44,96 & 47,53 & 1,21 & 1,37 & 1,40 & 1,34 \\
\hline Mucuna-preta & 52,15 & 48,50 & 44,88 & 47,61 & 1,26 & 1,37 & 1,39 & 1,31 \\
\hline C.V. $(\%)$ & 6,03 & 7,32 & 7,88 & 5,06 & 8,42 & 7,67 & 5,79 & 3,32 \\
\hline
\end{tabular}

${ }^{1}$ Dias após a semeadura do milho.

TABELA 3. Características químicas de amostras de solo retiradas na época de florescimento do feijão, em decorrência da incorporação dos restos culturais de milho, mucuna-preta e lab-lab, na região e Selvíria, MS, 1995 $^{1}$.

\begin{tabular}{lccccccc}
\hline \multirow{2}{*}{ Tratamento } & M.O. & $\mathrm{pH}$ & $\mathrm{P}-\mathrm{resina}$ & $\mathrm{K}$ & $\mathrm{Ca}$ & $\mathrm{Mg}$ & $\mathrm{V}$ \\
& $\left(\mathrm{g} \mathrm{kg}^{-1}\right)$ & $\left(\mathrm{CaCl}_{2}\right)$ & $\left(\mathrm{mg} \mathrm{dm}^{-3}\right)$ & ------- & $\left(\mathrm{mmol}_{\mathrm{c}} \mathrm{dm}^{-3}\right)$ & ------- & $(\%)$ \\
\hline Milho & 25,7 & 5,2 & 24 & $1,5 \mathrm{a}$ & 29,0 & 12,3 & 58 \\
Milho + mucuna-preta aos 75 DAS & 25,5 & 5,1 & 17 & $1,2 \mathrm{abc}$ & 25,5 & 13,5 & 55 \\
Milho + mucuna-preta aos 100 DAS & 25,0 & 5,2 & 17 & $1,3 \mathrm{ab}$ & 29,5 & 14,7 & 59 \\
Milho + lab-lab aos 75 DAS & 23,2 & 5,1 & 24 & $1,2 \mathrm{abc}$ & 27,5 & 12,0 & 55 \\
Milho + lab-lab aos 100 DAS & 24,0 & 5,0 & 16 & $1,4 \mathrm{ab}$ & 23,5 & 13,0 & 55 \\
Lab-lab & 24,5 & 5,2 & 19 & $0,9 \mathrm{bc}$ & 27,0 & 16,7 & 59 \\
Mucuna-preta & 23,0 & 5,0 & 19 & $0,8 \mathrm{c}$ & 24,5 & 12,0 & 54 \\
\hline C.V. (\%) & 7,61 & 3,73 & 37,58 & 16,06 & 14,01 & 27,53 & 8,7 \\
\hline
\end{tabular}

${ }^{1}$ Médias seguidas de mesma letra, na coluna, não diferem estatisticamente entre si pelo teste de Tukey a $5 \%$ de probabilidade

2 Dias após a semeadura do milho. 
Os resultados obtidos na avaliação da matéria seca de plantas e teores de macronutrientes nas folhas do feijoeiro estão apresentados na Tabela 4. Por esses dados, observa-se que houve efeito significativo de restos culturais, e os tratamentos com adubos verdes (lab-lab e mucuna-preta) propiciaram a obtenção de maior quantidade de matéria seca. Quanto aos teores de nutrientes, houve efeito significativo da adubação nitrogenada e de restos culturais em relação ao nitrogênio, e da adubação nitrogenada, em relação ao S. Apesar de a adubação em cobertura com $45 \mathrm{~kg} \mathrm{ha}^{-1}$ de $\mathrm{N}$ não interferir na produção de matéria seca das plantas, propiciou aumento no teor do nutriente nas folhas. Quanto aos restos culturais, os maiores teores foram encontrados nos tratamentos com mucuna-preta e lab-lab, com teores de 32,32 e $27,91 \mathrm{~g} \mathrm{~kg}^{-1}$, respectivamente. Nos demais tratamentos, o teor variou de 21,44 a $22,84 \mathrm{~g} \mathrm{~kg}^{-1}$. Quanto ao $\mathrm{S}$, observa-se que a ausência da adubação nitrogenada com uréia propiciou a obtenção de maior teor do nutriente nas folhas do feijoeiro; talvez tenha ocorrido a diluição do nutriente nas plantas que receberam adubação com $\mathrm{N}$.

No presente trabalho, não foi observada variação nos teores de $\mathrm{K}$ em face dos tratamentos utilizados. Já Miyasaka et al. (1966), estudando o comportamento de leguminosas e gramíneas em decomposi- ção, verificaram aumento no teor de K nas folhas do feijoeiro cultivado em sucessão.

Os valores obtidos na avaliação das características agronômicas do feijoeiro estão apresentados na Tabela 5, onde se pode observar efeito significativo da incorporação de restos culturais sobre o número de vagens e de grãos e os tratamentos com adubação verde em cultivo solteiro propiciaram a obtenção dos maiores valores.

Já o peso de 100 grãos sofreu influência apenas da adubação nitrogenada, onde a aplicação de $45 \mathrm{~kg} \mathrm{ha}^{-1}$ de N em cobertura propiciou a obtenção de grãos mais pesados.

Quanto à produção de grãos, houve efeito significativo da adubação em cobertura e também dos restos culturais. Quanto à adubação nitrogenada, apesar de não ter sido observado efeito sobre o número de vagens, grãos e grãos/vagem, o peso de 100 grãos foi influenciado, ou seja, o fornecimento de $\mathrm{N}$ propiciou a obtenção de grãos mais pesados, e, conseqüentemente, maior produção de grãos. Quanto aos restos culturais, o maior rendimento de grãos foi obtido no tratamento com incorporação de mucuna-preta $(2.407 \mathrm{~kg} / \mathrm{ha})$, o que está em desacordo com Abboud \& Duque (1986), que observaram efeito alelopático aparente da mucuna-preta so-

TABELA 4. Matéria seca de plantas e teores de nutrientes na parte aérea do feijoeiro, em decorrência da incorporação dos restos culturais de milho, mucuna-preta e lab-lab e da adubação nitrogenada em cobertura, na região de Selvíria, MS, 1995 1.

\begin{tabular}{|c|c|c|c|c|c|c|c|c|}
\hline \multicolumn{2}{|c|}{ Tratamento } & \multirow{2}{*}{$\begin{array}{c}\begin{array}{c}\text { Matéria seca } \\
\text { de plantas } \\
\left.\text { (g planta }^{-1}\right)\end{array} \\
7,53\end{array}$} & \multirow{2}{*}{$\begin{array}{c}\mathrm{N} \\
--\cdot-- \\
22,26 b\end{array}$} & \multirow{2}{*}{$\begin{array}{c}P \\
3,46\end{array}$} & $\begin{array}{c}\mathrm{K} \\
---(\mathrm{g} \mathrm{k} \\
\end{array}$ & $\begin{array}{l}\mathrm{Ca} \\
-1\end{array}$ & $\mathrm{Mg}$ & 246 \\
\hline Adubação em & $0 \mathrm{~kg} \mathrm{ha}^{-1}$ de $\mathrm{N}$ & & & & $\begin{array}{l}26,35 \\
28,05\end{array}$ & 20,80 & $\begin{array}{l}7,22 \\
6,75\end{array}$ & $2,46 a$ \\
\hline & & & & & & & & \\
\hline Restos & Milho & $7,17 \mathrm{ab}$ & $21,52 c$ & 3,50 & 26,77 & 19,65 & 6,45 & 2,36 \\
\hline \multirow[t]{6}{*}{ culturais } & Milho + mucuna-preta aos 75 DAS $^{2}$ & $6,68 b$ & $22,75 \mathrm{c}$ & 3,50 & 26,99 & 21,05 & 7,11 & 2,19 \\
\hline & Milho + mucuna-preta aos 100 DAS & $8,07 \mathrm{ab}$ & $21,44 c$ & 4,05 & 26,56 & 21,00 & 7,08 & 2,40 \\
\hline & Milho + lab-lab aos 75 DAS & $7,07 \mathrm{~b}$ & $21,83 c$ & 3,54 & 26,77 & 20,65 & 7,08 & 2,50 \\
\hline & Milho + lab-lab aos 100 DAS & $7,27 \mathrm{ab}$ & $22,84 \mathrm{c}$ & 3,52 & 25,56 & 20,75 & 6,18 & 2,25 \\
\hline & Lab-lab & $9,54 \mathrm{a}$ & $27,91 \mathrm{~b}$ & 3,45 & 27,20 & 22,50 & 7,02 & 2,22 \\
\hline & Mucuna-preta & $9,52 \mathrm{a}$ & $32,32 \mathrm{a}$ & 3,62 & 29,54 & 22,85 & 7,98 & 2,09 \\
\hline C.V. $(\%)$ & & 19,96 & 11,26 & 22,47 & 12,63 & 11,96 & 18,79 & 12,47 \\
\hline
\end{tabular}


TABELA 5. Características agronômicas do feijoeiro, decorrentes da incorporação dos restos culturais de milho e/ou mucuna-preta e lab-lab e da adubação nitrogenada em cobertura, na região de Selvíria, MS, 1995'.

\begin{tabular}{|c|c|c|c|c|c|c|}
\hline \multicolumn{2}{|c|}{ Tratamento } & \multirow{2}{*}{$\begin{array}{c}\mathrm{N}^{\mathrm{o}} \text { de vagens } \\
\text { planta }^{-1}\end{array}$} & \multirow{2}{*}{$\begin{array}{c}\begin{array}{c}\mathrm{N}^{\mathrm{o}} \text { de grãos } \\
\text { planta }^{-1}\end{array} \\
45,53\end{array}$} & \multirow{2}{*}{$\begin{array}{c}\begin{array}{c}\mathrm{N}^{\mathrm{o}} \text { de grãos } \\
\text { vagem }^{-1}\end{array} \\
4,82\end{array}$} & \multirow{2}{*}{$\begin{array}{c}\text { Peso de } 100 \\
\text { grãos }(\mathrm{g})\end{array}$} & \multirow{2}{*}{$\begin{array}{c}\begin{array}{c}\text { Produção de } \\
\text { grãos }\left(\mathrm{kg} \mathrm{ha}^{-1}\right)\end{array} \\
1.550 \mathrm{~b}\end{array}$} \\
\hline Adubação em & $0 \mathrm{~kg} \mathrm{ha}^{-1}$ de $\mathrm{N}$ & & & & & \\
\hline cobertura & $45 \mathrm{~kg} \mathrm{ha}^{-1}$ de $\mathrm{N}$ & 10,29 & 48,90 & 4,71 & $23,29 \mathrm{a}$ & $1.827 \mathrm{a}$ \\
\hline Restos & Milho & $8,19 \mathrm{c}$ & $38,86 \mathrm{~b}$ & $4,71 \mathrm{ab}$ & 22,25 & $1.189 \mathrm{c}$ \\
\hline \multirow[t]{6}{*}{ culturais } & Milho + mucuna-preta aos $75 \mathrm{DAS}^{2}$ & $8,52 \mathrm{c}$ & $37,98 b$ & $4,46 a b$ & 22,52 & $1.463 b c$ \\
\hline & Milho + mucuna-preta aos 100 DAS & $10,76 \mathrm{abc}$ & $53,16 \mathrm{ab}$ & $4,98 \mathrm{ab}$ & 22,94 & $1.981 \mathrm{ab}$ \\
\hline & Milho + lab-lab aos 75 DAS & $8,82 \mathrm{bc}$ & $37,98 b$ & $4,21 \mathrm{~b}$ & 22,19 & $1.167 \mathrm{c}$ \\
\hline & Milho + lab-lab aos 100 DAS & $8,01 \mathrm{c}$ & $39,49 b$ & $4,95 \mathrm{ab}$ & 22,16 & $1.464 \mathrm{bc}$ \\
\hline & Lab-lab & $12,56 \mathrm{a}$ & $60,62 \mathrm{a}$ & $4,78 \mathrm{ab}$ & 23,50 & $2.149 \mathrm{ab}$ \\
\hline & Mucuna-preta & $11,86 \mathrm{ab}$ & $62,44 \mathrm{a}$ & $5,27 \mathrm{a}$ & 23,37 & $2.407 \mathrm{a}$ \\
\hline C.V. $(\%)$ & & 21,77 & 28,38 & 11,88 & 4,67 & 26,80 \\
\hline
\end{tabular}

1 Médias seguidas de mesma letra, na coluna para cada parâmetro estudado (adubação em cobertura ou restos culturais), não diferem estatisticamente entre si pelo teste de Tukey a $5 \%$ de probabilidade.

${ }^{2}$ Dias após a semeadura do milho

bre o feijão, não diferindo significativamente do tratamento com lab-lab (2.149 $\left.\mathrm{kg} \mathrm{ha}^{-1}\right)$ e milho + mucunapreta aos 100 dias $\left(1.981 \mathrm{~kg} \mathrm{ha}^{-1}\right)$. A menor produção de grãos foi observada nos tratamentos com milho solteiro (1.189 $\left.\mathrm{kg} \mathrm{ha}^{-1}\right)$ e milho + lab-lab, aos 75 DAS $\left(1.167 \mathrm{~kg} \mathrm{ha}^{-1}\right)$. Portanto, o tratamento com incorporação de mucuna-preta produziu praticamente o dobro de grãos de feijão em relação ao tratamento com incorporação apenas de palhada de milho. Tais dados são confirmados por Chagas et al. (1992), citados por Chagas (1994), que observaram que o cultivo do feijão após mucuna e milho proporcionou aumento de 39,2 e $10,9 \%$ no rendimento, respectivamente.

É interessante mencionar que foi detectada a presença de nematóides formadores de galhas na área de cultivo. Durante a colheita, pôde-se observar que os tratamentos com incorporação, principalmente de mucuna-preta e lab-lab em cultivo solteiro, apresentavam plantas de feijão com menor dano no sistema radicular. Sharma (1982) também verificou que os adubos verdes crotalária, lab-lab, mucuna e outros foram altamente eficientes na redução da população ativa de nematóides fitoparasitas e saprófagos. Também Ferraz et al. (1977), citados por Tanaka et al. (1992), verificaram que a mucuna-preta pode controlar nematóides e algumas espécies de plantas daninhas.

\section{CONCLUSÕES}

1. O tratamento com incorporação de mucuna-preta produz praticamente o dobro de grãos de feijão em relação ao tratamento com incorporação apenas de palhada de milho.

2. As maiores produtividades são obtidas nos tratamentos com incorporação de mucuna-preta, lablab e milho + mucuna-preta semeada 100 dias após a semeadura do milho.

3. A aplicação de $45 \mathrm{~kg} \mathrm{ha}^{-1}$ de $\mathrm{N}$ aumenta em $17,8 \%$ a produtividade média do feijoeiro.

\section{REFERÊNCIAS}

ABBOUD, A.C. de S.; DUQUE, F.F. Efeitos de materiais orgânicos e vermiculita sobre a seqüência feijão-milho-feijão. Pesquisa Agropecuária Brasileira, Brasília, v.21, n.3, p.227-236, 1986.

ALVARENGA, R.C.; COSTA, L.M. da; MOURA FILHO, W.; REGAZZI, A.D. Características de alguns adubos verdes de interesse para a conservação e recuperação de solos. Pesquisa Agropecuária Brasileira, Brasília, v.30, n.2, p.175-185, 1995

BLAKE, G.R.; HARTGE, K.H. Bulk density. In: KLUTE, A. (Ed.). Methods of soil analysis: physical and mineralogical methods. 2.ed. Madison: Am. Soc. Agron., 1986. p.363-382.

Pesq. agropec. bras., Brasília, v.34, n. 11, p.2029-2036, nov. 1999 
BULISANI, E.A.; ALMEIDA, L.D'A.; ROSTON, A.J A cultura do feijoeiro no Estado de São Paulo. In BULISANI, E.A. (Coord.). Feijão: fatores de produção e qualidade. Campinas: Fundação Cargill, 1987. p.29-88.

CHABARIBERY, D. Tecnologia socialmente apropriada: adubação verde. São Paulo: Instituto de Economia Agrícola , 1988. 26p. (Relatório de Pesquisa, $1 / 88)$.

CHAGAS, J.M. Considerações sobre a cultura do feijão no inverno em Minas Gerais. Feijão no inverno. Informe Agropecuário, v. 17, p.5-8, 1994.

DONEGÁ, I.M. Comportamento de leguminosas adubos verdes cultivadas no outono/inverno, em três populações de plantas. Ilha Solteira: UNESP/FEIS, 1994. 75 p.

FAGERIA, N.K. Manejo químico do solo. In: FERREIRA M.E.; YAMADA, T.; MALAVOLTA, E. (Eds.) Cultura do arroz de sequeiro: fatores afetando a produtividade. Piracicaba: Instituto da Potassa e do Fosfato - Instituto Internacional da Potassa, 1983. p. $239-260$

HERNANI, L.C.; ENDRES, V.C.; PITOL, C.; SALTON, J.C. Adubos verdes de outono/inverno no Mato Grosso do Sul. Dourados: Embrapa-CPAO, 1995. $93 p$.

IAPAR. Recomendações técnicas para a cultura do trigo no Paraná. Londrina: IAPAR, 1995. 98p. (Circular, 86).

KIEHL, E.J. Fertilizantes orgânicos. Piracicaba: Agronômica Ceres, 1985. 492p.
KRAMM, V.E.M.; VIEIRA, C.; SILVA, J.F; CARDO$\mathrm{SO}, \mathrm{A} . \mathrm{A}$. Efeitos da competição com plantas daninhas sobre a cultura do feijão (Phaseolus vulgaris L.). Revista Ceres, v.37, p.345-361, 1990.

MIYASAKA, S.; CAMARGO, A.P.; INFORZATO, R.; IGUE, T. Efeitos da cobertura e da incorporação ao solo, imediatamente antes do plantio, de diferentes formas de matéria orgânica não decomposta, na cultura do feijoeiro. Bragantia, v.25, p.349-363, 1966.

RAIJ, B. van; QUAGGIO, J.A. Métodos de análise de solo para fins de fertilidade. Campinas: Instituto Agronômico, 1983. 31p. (Boletim técnico, 81).

SARRUGE, J.R.; HAAG, H.P. Análises químicas em plantas. Piracicaba: USP-ESALQ, 1974. 56p

SHARMA, R.D. Eficiência de adubos verdes no controle de nematóides associados à soja nos cerrados. Planaltina: Embrapa-CPAC, 1982. 30p.

SILVA, E.M.R.; ALMEIDA, D.L. de; FRANCO, A.A.; DÖBEREINER, J. Adubação verde no aproveitamento do fosfato em solo ácido. Revista Brasileira de Ciência do Solo, v.9, p.85-88, 1985

TANAKA, R.T.; MASCARENHAS, H.A.A.; DIAS, O.S.; CAMPIDELLI, C.; BULISANI, E.A. Cultivo da soja após incorporação de adubo verde e orgânico. Pesquisa Agropecuária Brasileira, Brasília, v.27, n.11, p.1477-1483, 1992.

VOMOCIL, J.A. Porosity. In: BLACK, C.A. (Ed.) Methods of soil analysis. Madison: American Society of Agronomy, 1965. pt.1, p.299-314. 